\title{
Variation of stomatal resistance with leaf age in Quercus petraea: effect on the soil-water balance of an oak forest
}

\author{
J. Nizinski, D. Morand and B. Saugier \\ Laboratoire d'Ecologie Végétale, CNRS URA121, Bâtiment 362, Université de Paris-Sud, 91405 \\ Orsay Cedex, France
}

\section{Introduction}

In deciduous forests, evapotranspiration follows variations in the leaf area index $(L A I)$. It is thus expected to reach a maximum in spring when the $L A I$ reaches a plateau and when the soil water supply is adequate. From a detailed study of the soil-water balance over $3 \mathrm{yr}$, we found that evapotranspiration reached a maximum nearly 1 mo after the leaf area index (Nizinski and Saugier, 1988; 1989a, b). We thus decided to study the effect of leaf age on stomatal resistance and on the morphology of the leat epidermis.

\section{Materials and Methods}

Study site: 2 stands of $Q$. petraea (Matt.) Liebl. in the Fontainebleau forest (1981-1983) and on the Orsay campus (1987); soil-water balance measurements: rain gauges, stemflow collars, neutron probe; stomatal resistance (Delta T Mk3 porometer) in the middle of the day; leaf size (Delta $T$ area meter) and the observation of the abaxial epidermis (scanning electron microscope).

\section{Observations related to the soil-water balance}

Fig. 1 shows the strong decrease in stomatal resistance with leaf age, expressed as the ratio of actual leaf area to its maximal area. All these values were obtained at high light intensity and ample water supply. This curve is repeated in Fig. 2b, which shows a further decrease in stomatal resistance after full leaf development (Fig. 2a). The decrease in stomatal resistance led to a progressive increase in the ratio of real transpiration to potential (Penman) evaporation (T/ETP) from 0 at bud burst to about 0.5 at the end of leaf growth and to 0.8 at the end of June.

\section{Morphology of leat epidermis}

Scanning electron microscopy of the leaf epidermis revealed: 1) young leaves have 


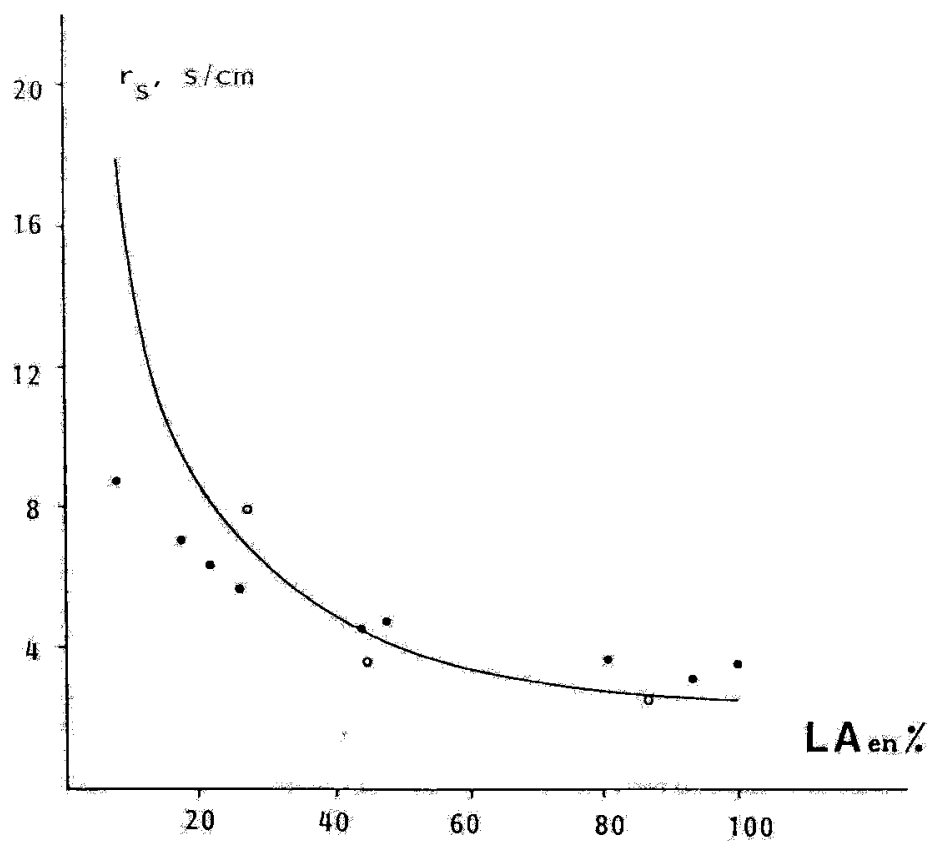

Fig. 1. Variation of stomatal resistance with leaf age, expressed as the ratio of actual leaf area to maximal leaf area. O. Fontainebleau, 1983; O: Orsay 1987.

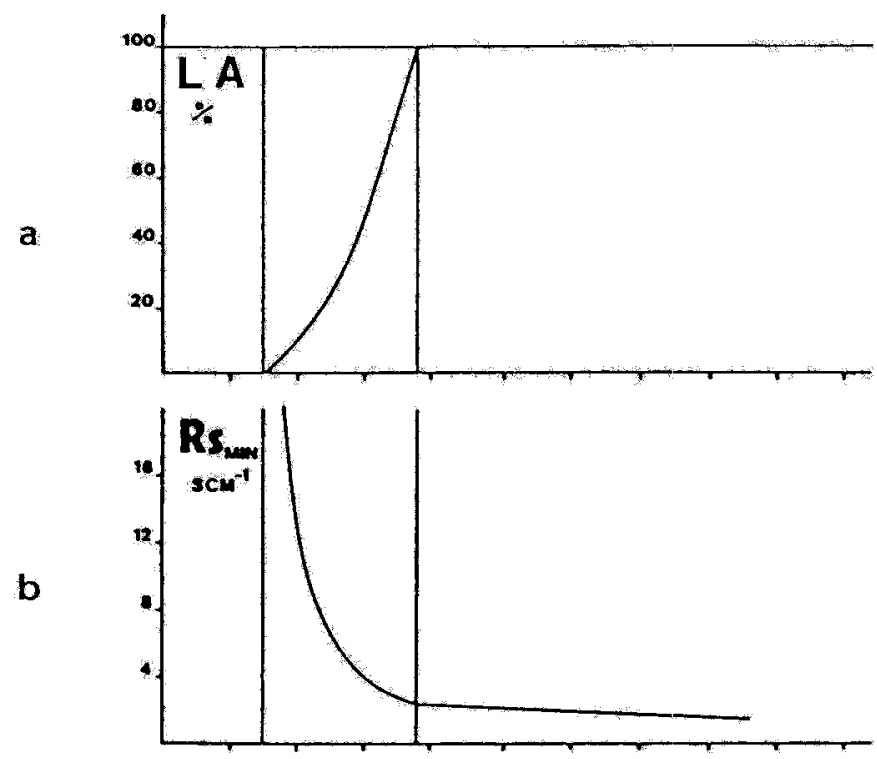

Fig. 2. Variations as a function of time of as leaf area (relative values) b: stomatal resistance; $c$ : real to potential evapotranspiration (TETP) and soil water reserve $(R P)$ as \% of field capacity: 
Fig. 2 continued.

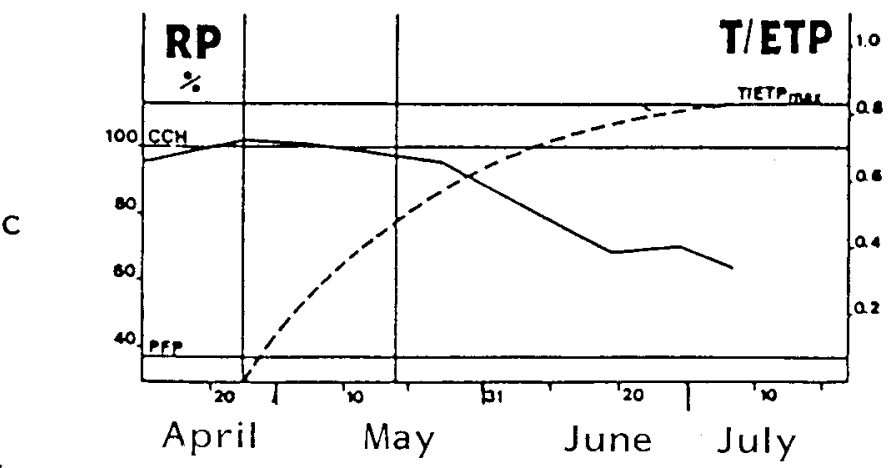

a

b

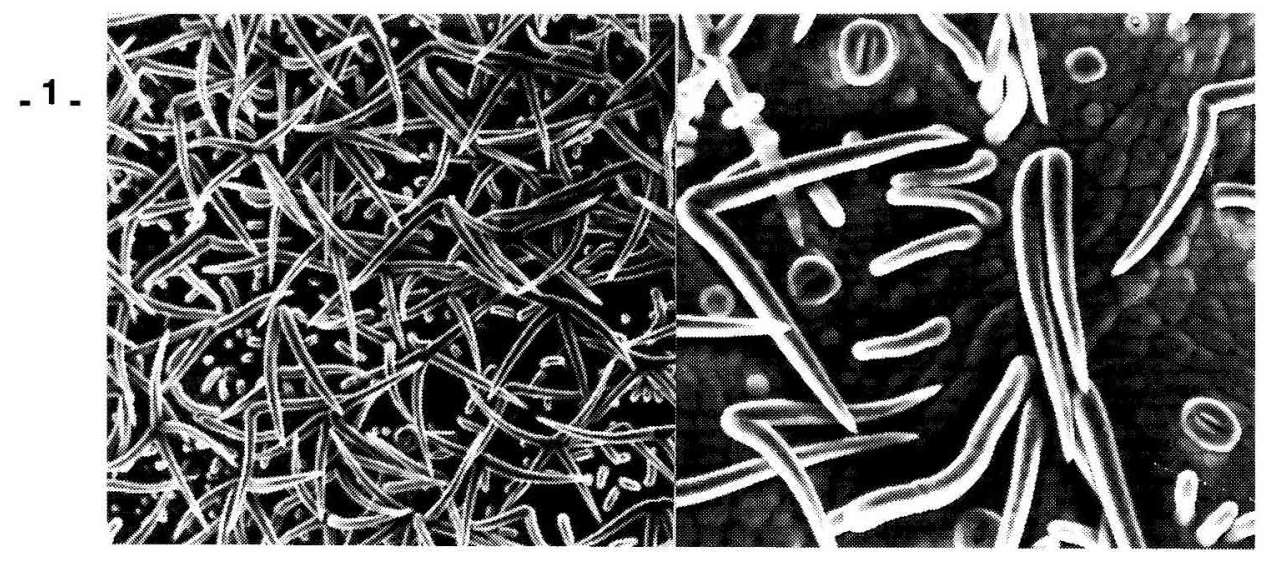

a

b

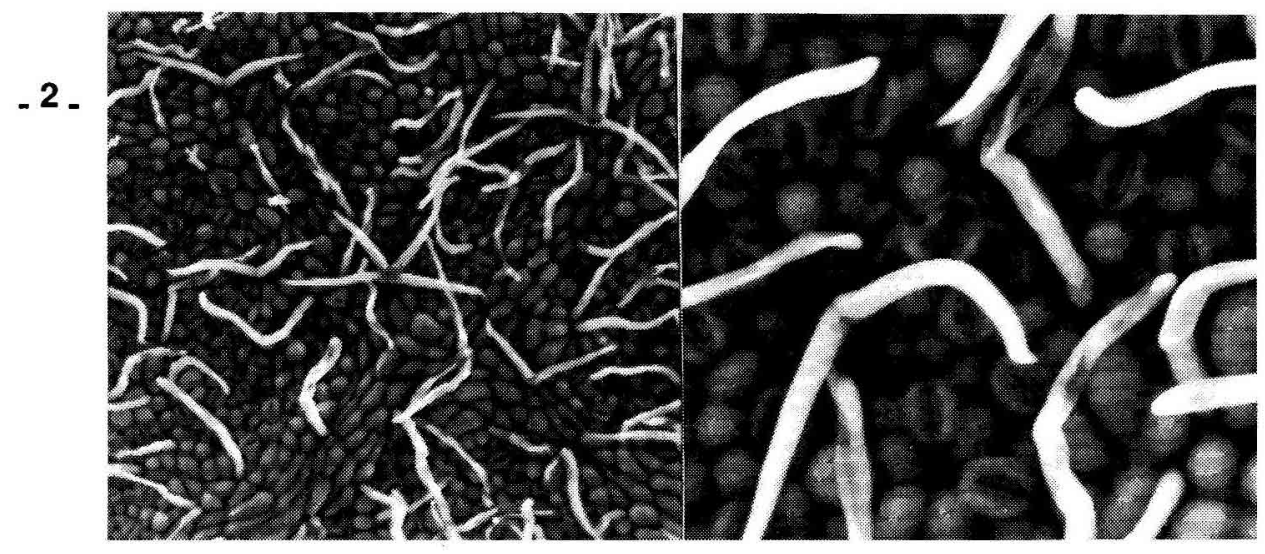

Fig. 3. Scanning electron micrographs of leaf epidermis observed on: 1: 24 April 1987, $L A=8 \% L A_{\max }, r_{\mathrm{s}}=$ $8.7 \pm 3.6 \mathrm{~s} / \mathrm{cm} ; 2: 14$ May $1987, L A=100 \% L A_{\max }, r_{\mathrm{s}}=3.6 \pm 0.9 \mathrm{~s} / \mathrm{cm}(\mathbf{a} \times 120 ; \mathbf{b} \times 300$. 
stomates that have not achieved their development. They are covered with a dense net of hairs (Fig. 3, 1a and 2a); 2) as the leaf matures, all stomates end their development and hairs progressively disappear (Fig. 3, 1b and 2b). The decrease in epidermal resistance after the leaf has reached its full size may thus be attributed to both stomatal development and a decrease in boundary layer resistance.

\section{References}

Nizinski J. \& Saugier B. (1988) A model of leaf budding and development for a mature Quercus forest. J. Appl. Ecol. 25, 643-652

Nizinski J. \& Saugier B. (1989a) Dynamique de l'eau sous chênaie (Quercus petraea (Matt.) Liebl.) en forêt de Fontainebleau. Ann. Sci. For. 46, 173-186

Nizinski J. \& Saugier B. (1989b) A model of transpiration and soil-water balance for a mature oak forest. Agric. For. Meteorol, in press 